\title{
TRANSITIONAL NOTES
}

SciBX

Science-Business eXchange

\section{Buddy system for orphan disease}

\section{By Lev Osherovich, Senior Writer}

The Wellcome Trust has launched a program to fund early stage translational research in rare and orphan diseases. Participation in the program, dubbed the Pathfinder Award Scheme, requires academics or not-for-profits to pair up with an industry partner at the outset.

Industry partners will contribute expertise and project-specific services but are not required to contribute cash. Companies participating in the scheme receive rights of first refusal for new IP arising from the partnership.

In September, Wellcome awarded 2 grants of about $£ 100,000$ (US $\$ 160,000$ ) each to 2 academic-industry pairs and plans to fund at least 2 more similar-sized grants within a year.

A team at University College London will work with Eli Lilly and Co. to develop cell culture models for a rare class of neurodegenerative disorders that resemble Parkinson's disease (PD). A University of Oxford group will work with Pfizer Inc. to develop methods to treat homocystinuria, a rare metabolic disease.

Bethan Hughes, a Wellcome Trust business analyst who administers the Pathfinder Scheme, said the program was conceived to finance projects that cannot compete for the Trust's other translational grant programs, which are typically $£ 2-3$ million (US $\$ 3.2-4.8$ million) and require a more advanced starting point.

"There were many times when applications would come to us in orphan or neglected diseases but were too early for those other funding schemes," said Hughes. "It was considered a great shame that these proposals didn't have access to product development expertise" to help them get to a more advanced stage.

Indeed, the rationale for engaging industry partners at the start of a project is to help the academics build the right tools and reagents for future translational efforts.

Hughes said rare disease researchers in academia often lack access to industrial expertise and do not know what milestones are relevant or how to navigate the regulatory landscape. The result can be inadequately validated disease models and wasted effort on inappropriate drug delivery methods.

"Suppose you're making a protein-based vaccine. Academic researchers may not know what kind of vector or tag would be most suitable and might be rushing to get to proof of concept with less than ideal technology," said Hughes. "It doesn't do much service in the end to put a suboptimal drug candidate into the clinic."
One caveat of the Pathfinder Award program is that it requires the industry partner to have previously brought a product to market. This effectively means researchers will need to work with pharmas and large biotechs rather than the small startups that populate the orphan disease space.

The reason for requiring industry partners to have prior product development experience is that "the expertise that we want these academic groups to harness may only be available" from such partners, according to Hughes.

\section{Metal and metabolism}

The UCL-Lilly team, led by molecular neuroscience professor John Hardy, will build cell culture models of neurodegeneration with brain iron accumulation (NBIA), a rare hereditary PD-like condition.

NBIA is caused by mutations in any of three genes-pantothenate kinase 2 (PANK2; NBIA1), phospholipase $A_{2}$ group VI ( $P L A_{2} G 6$; NBIA2A) and ferritin light polypeptide (FTL; NBIA3). NBIA affects fewer than one in a million people and leads to clinical and histopathological features that resemble severe early onset PD. The disease is thought to be driven by excessive iron accumulation, which is observed to a lesser extent in milder forms of PD.

Hardy aims to "collect fibroblasts from NBIA patients and transform them into neurons in vitro," which would allow him and Lilly researchers to screen for compounds that reduce iron accumulation.

Hardy and his collaborators at Lilly hope to show that NBIA is a valid model of the sporadic form of PD.

Hardy said obtaining funding for the project through other grant mechanisms has been challenging because there is not yet a consensus about the relationship between NBIA and PD.

"It will be a while before the entire research community is convinced that this is a good model for PD," said Hardy. Funding this proposal "would be difficult if we got into peer review with people who didn't think this was any more than a small disease."

After 18 months, the grant expires and Lilly will have an option to continue the joint project under a direct collaborative research agreement.

At least one company-Prana Biotechnology Ltd.-aims to treat PD by reducing iron accumulation in the brain. Prana's PBT-434, a metal-binding compound, is in preclinical development for PD.

The other announced Pathfinder Award recipient is Wyatt Yue, group leader in the structural genomics of metabolic enzymes group at the Structural Genomics Consortium at University of Oxford.

Yue and collaborators at Pfizer will apply structural methods to develop pharmacological tools to restore the function of cystathionine $\beta$-synthase (CBS). Mutations in CBS lead to homocystinuria, in which homocysteine accumulation leads to a broad range of neurological and musculoskeletal problems.

Homocystinuria is currently treated by a combination of N,N,Ntrimethylglycine, vitamin $\mathrm{B}_{6}$ and a diet low in the amino acid methionine. Cystadane betaine anhydrous, a formulation of $\mathrm{N}, \mathrm{N}, \mathrm{N}-$ trimethylglycine, is marketed by Rare Disease Therapeutics Inc. in the U.S. and Orphan Europe S.a.r.l. elsewhere. 


\section{ANALYSIS}

Osherovich, L. SciBX 5(39); doi:10.1038/scibx.2012.1020

Published online Oct. 4, 2012

COMPANIES AND INSTITUTIONS MENTIONED

Eli Lilly and Co. (NYSE:LLY), Indianapolis, Ind.

Orphan Europe S.a.r.l., Paris, France

Pfizer Inc. (NYSE:PFE), New York, N.Y.

\section{TRANSITIONAL NOTES}

Prana Biotechnology Ltd. (ASX:PBT; NASDAQ:PRAN), Melbourne, Victoria, Australia

Rare Disease Therapeutics Inc., Franklin, Tenn.

Structural Genomics Consortium, Oxford, U.K.

University College London, London, U.K.

University of Oxford, Oxford, U.K.

Wellcome Trust, London, U.K. 